Int. J. Plant Sci. 165(6):1039-1045. 2004.

(c) 2004 by The University of Chicago. All rights reserved.

$1058-5893 / 2004 / 16506-0012 \$ 15.00$

\title{
COROLLA MORPHOLOGY FACILITATES BOTH AUTOGAMY AND BUMBLEBEE POLLINATION IN MIMULUS GUTTATUS
}

\author{
H. S. Arathi and John K. Kelly ${ }^{1}$ \\ Biology Department, Adelphi University, Garden City, New York 11530, U.S.A.; and Department of Ecology and \\ Evolutionary Biology, University of Kansas, 1200 Sunnyside Avenue, Lawrence, Kansas 66045, U.S.A.
}

\begin{abstract}
The showy corolla of Mimulus guttatus is generally considered an adaptation to attract pollinators. We use phenotypic manipulations to demonstrate that corolla morphology plays a critical mechanical role in both outcrossing and self-fertilization. In the absence of pollinators, the lower portion of the corolla facilitates autogamy by retaining pollen released from the anthers. A substantial portion of self-fertilization seems to occur late in the floral life span as the stigma contacts the corolla. When pollinators are present, the corolla facilitates outcrossing before, during, and after insect visitation. A large fraction of cross-pollen is actually captured by the corolla and not by the stigma. This "indirect" pathway for pollen reception suggests that a large fraction of cross-pollination in M. guttatus actually occurs long after a pollinator departs from a flower.
\end{abstract}

Keywords: Bombus impatiens, bumblebees, monkey flower, Mimulus guttatus, phenotypic manipulation, pollen-collecting hairs.

\section{Introduction}

Most flowering plants depend on animals for pollination. Natural selection has molded floral characters to several distinct requirements for successful reproduction. The flower must first recruit pollinators and then successfully facilitate the physical transmission of pollen to and from the pollinator. Corolla morphology is essential to both of these requirements. The corolla obviously serves as an attractive structure in many species, as variations in its size, shape, and coloration are clearly related to the perceptive capabilities and behavioral tendencies of pollinators (Sprengel 1793; Grant 1966; Kevan 1978). Botanists have also long appreciated that the corolla may also play a critical role in the mechanical receipt and dissemination of pollen. For example, the corolla of the orchid Catasetum saccatum is modified into a "spring trap" that fires pollinia onto the thorax of visiting bees (Darwin 1877; Futuyma 1998, pp. 338-339). A less dramatic but perhaps more common role for the corolla may be through "secondary pollen presentation" (Carolin 1960; Faegri and Van der Pijl 1979, p. 22), wherein pollen released from the anthers is collected and retained by the corolla. This pollen may be subsequently transmitted to a pollinator or used for self-fertilization (Nyman 1993; Kalisz et al. 1999; Anderson et al. 2000).

In this article, we explore the mechanical role of corolla morphology in both outcrossing and self-fertilization of Mimulus guttatus (Scrophulariaceae). Mimulus guttatus produces zygomorphic yellow flowers, each with four anthers and a single pistil (fig. 1). The petals are fused, and the co-

\footnotetext{
${ }^{1}$ Author for correspondence; telephone 785-864-3706; fax 785864-5860; e-mail jkk@ku.edu.
}

Manuscript received October 2003; revised manuscript received May 2004. rolla is a single, continuous structure with distinct upper and lower portions (fig. $1 B$ ). A large number of small, fine hairs protrude from the lower portion of the corolla. We hypothesize that these hairs collect pollen (Shetler 1979), trapping it both from the anthers of that flower (self-pollen) and from insects carrying pollen from other plants (cross-pollen). Transfer of pollen from these hairs to the stigmatic surface may assure successful reproduction when there is reduced pollinator activity or when pollen transfer is inefficient.

Facilitation of outcrossing may be particularly important in M. guttatus because it has a touch-sensitive stigma. The forward portion of the stigma is a mouthlike structure that closes following physical contact (fig. 1A). It will later reopen if the pistil has not received sufficient pollen (Faegri and Van der Pijl 1979, p. 40). The rapid closure of the stigma limits direct pollen transfer during each pollinator visit. The amount of pollen deposited on the stigma is usually only a small fraction of that carried by the pollinator (Harder and Thomson 1989). In fact, much of it may be deposited on other parts of the flower as the insect forages. Indirect crosspollination occurs if this pollen is later transferred from the corolla to the stigma.

Phenotypic manipulation provides a simple and direct means to assess the functional significance of a trait (Waser 1983; Mitchell-Olds and Shaw 1987; Wade and Kalisz 1990). In this article, we describe a series of five phenotypic manipulations designed to determine the mechanical role of the corolla in pollination. Specifically, we removed the lower portion of the corolla and with it the putative pollencollecting hairs (fig. $1 B$ ). This manipulation was applied to plants at different stages of floral development and in both the presence and absence of pollinators. The differences between these experiments allow us to distinguish a number of distinct ways in which corolla morphology facilitates reproduction. 


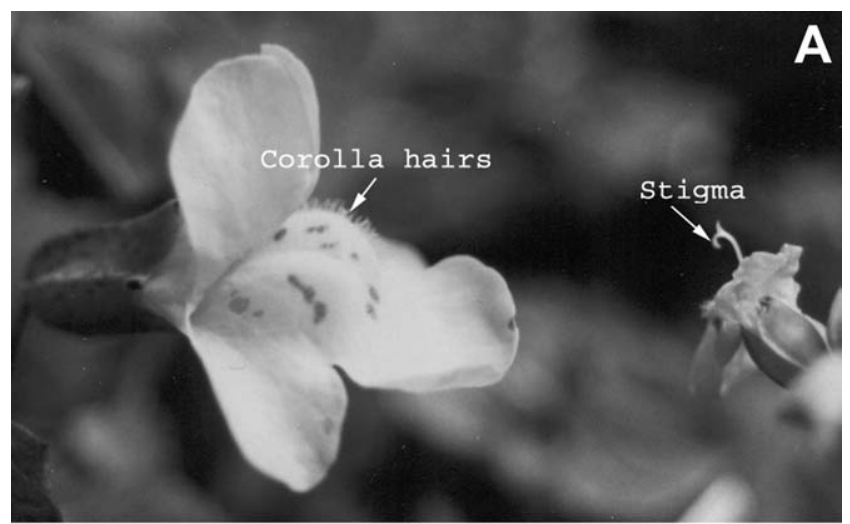

B

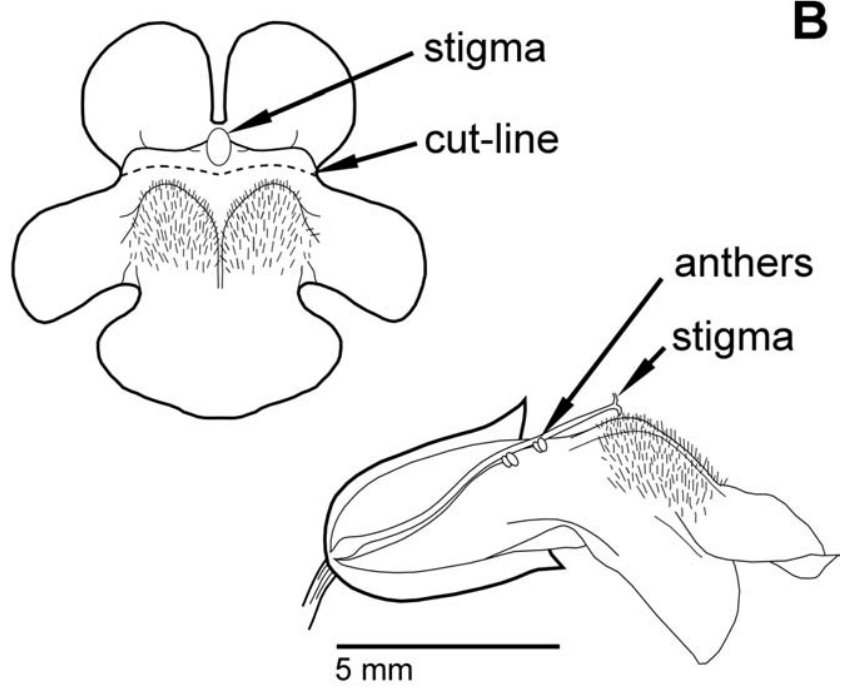

Fig. 1 Flower of Mimulus guttatus. A, Side-view photograph of two flowers illustrating the corolla hairs and stigma. The corolla and anthers have been pulled back to reveal the stigma and style on the left-hand flower. $B$, Line drawings of a front view and a side view. The cut line used in the phenotypic manipulation is illustrated in the front view. For the side view, the upper portion of the corolla has been removed to reveal the positions of the reproductive parts relative to the corolla hairs.

\section{Material and Methods}

\section{Overview}

Table 1 summarizes the key differences among the five experiments. The autogamy experiment was designed to determine the contribution of the lower corolla lip to selffertilization. Manipulation was imposed immediately upon anthesis, and plants were maintained in a pollinator-free environment through fruit maturation. To determine how the lower corolla lip affects outcrossing, we conducted two bumblebee pollination experiments in which experimental flowers were emasculated at anthesis and then placed within a pollination arena. Emasculation ensures that all seeds are outcrossed and that differences between control and manipulated flowers can be attributed to differences in the receipt of crosspollen. To distinguish pre- and postvisitation effects, we im- posed the manipulation both before and after exposing the plants to pollinators in different experiments.

We used surgical scissors to remove the lower lip of the corolla (fig. $1 B$ ). The manipulation did not affect the reproductive organs of the flower. We conducted two procedural control experiments to assure that differences between manipulated and control plants could be attributed to pollination effects and not to physiological or mechanical side effects of trimming (Waser 1983, p. 244; Dytham 1999, p. 26). A difference between trimmed and control plants within the hand-pollination experiment would indicate a physiological effect of manipulation, i.e., a wound response, on the reproductive capacity of the flower. A difference between trimmed and control plants within the corolla abscission experiment would indicate that manipulation affects the amount of time that the corolla is retained on a flower. This might, in turn, affect the ability of the flower to self-fertilize (Dole 1990).

\section{Study Population}

Mimulus guttatus is a species complex composed of many morphologically diverse but interfertile populations throughout western North America (Vickery 1978). This study used plants derived from a single natural population of M. guttatus located on Iron Mountain in the Cascade Mountains of Oregon (Willis 1996). The plants at Iron Mountain are annual (or winter annual) and predominantly outcrossing (Willis 1993). Individuals bolt from the seedling stage following snowmelt, usually during early June. They flower and then die, apparently of desiccation, ca. 1.5 mo later. The short growing season allows most plants to produce only a single flower in the field, although multiple flowers are produced during years with permissive conditions (N. Martin, personal communication). Flowers produced by Iron Mountain plants are a rich source of pollen but offer relatively little nectar (H. S. Arathi, unpublished results; also Robertson et al. 1999).

Seeds were collected from mature fruits at Iron Mountain during 1993, 1998, 1999, and 2000. In December 2000, a single plant from each field-collected maternal family was grown to maturity in the University of Kansas greenhouse. Among these unrelated parental plants, 479 were derived from the 1993 sample, 352 from the 1998 sample, 154 from the 1999 sample, and 207 from the year 2000 sample. These

Table 1

Summary of the Key Differences among the Five Experiments

\begin{tabular}{llcc}
\hline Experiment & $\begin{array}{c}\text { When are plants } \\
\text { manipulated? }\end{array}$ & $\begin{array}{c}\text { Are pollinators } \\
\text { present? }\end{array}$ & $\begin{array}{c}\text { Are the plants } \\
\text { emasculated? }\end{array}$ \\
\hline $\begin{array}{l}\text { Autogamy } \\
\text { Bumblebee } \\
\text { pollination 1 } \\
\text { Bumblebee } \\
\text { pollination 2 }\end{array}$ & Anthesis & Postpollination & Anthesis and \\
postpollination & Yes & No \\
$\begin{array}{l}\text { Hand-pollination } \\
\begin{array}{c}\text { Aorolla } \\
\text { abscission }\end{array}\end{array}$ & Anthesis & Yes & Yes \\
\hline
\end{tabular}


individuals were paired randomly and then crossed. The progeny of these crosses, 596 outbred full-sib families, constitute the Zia-1 base population. This base population, which is genetically representative of Iron Mountain, has been employed in several experiments. The seeds used for this experiment are unrelated grand progeny of the Zia-1 families, although there was no selection imposed on the two intervening generations.

The experiments were conducted on plants grown under controlled greenhouse conditions of $18 \mathrm{~h}$ light, a day temperature of $24^{\circ} \mathrm{C}$, and a night temperature of $15^{\circ} \mathrm{C}$. Outbred seeds were sown onto damp potting soil and individual seedlings transplanted into 2 -in pots $7 \mathrm{~d}$ after sowing. Beginning with $14 \mathrm{~d}$ after sowing, plants were fertilized every week using $10 \mathrm{~N}-30 \mathrm{P}-20 \mathrm{~K}$ at a concentration of $3.95 \mathrm{~g} \mathrm{~L}^{-1}$ of water. Plants began flowering $21 \mathrm{~d}$ after sowing and, at flowering, were randomly distributed into the five experiments. A single flower on each plant was used for the experimental manipulation. No plant was used in more than one experiment. Fruit was collected 1 mo after each experiment, and seeds were counted.

\section{Autogamy (Self-Fertilization) Experiment}

This experiment involved 112 plants assigned randomly into two categories, "trimmed" and "control." Manipulation was applied only to the former. There were an equal number of plants in each group, and all were maintained in a pollinatorfree greenhouse and allowed to self-pollinate naturally.

\section{Bumblebee Pollination Experiment 1}

A colony of Bombus impatiens, consisting of ca. 50 worker bees and a queen, was obtained from Koppert Biological Systems (Ann Arbor, Mich.). The bees had not foraged outside their box before arrival in the laboratory, but they did have access to pollen and sucrose solution. The colony box was placed in a netted cage $(1.5 \mathrm{~m} \times 1.5 \mathrm{~m} \times 0.9 \mathrm{~m})$ in a laboratory maintained at $25^{\circ} \mathrm{C}$, and the experiment was carried out in this cage. Before the experiment began, bumblebees were allowed to forage on the flowers of M. guttatus for 7-10 d. This period served to acclimatize the bees to these flowers and to the netted cage as the foraging arena. Throughout the experiment, worker bees foraged on the arrays of flowering plants described below. However, they also had ad lib. access to sucrose solution inside the colony box.

The floral arrays consisted of a mixture of background and experimental plants. The experimental plants were used to test for corolla facilitation of outcrossing. The background plants served to attract foraging bees and as a pollen source for cross-pollination. All seeds set by experimental flowers were derived from outcrossing with the background plants. The experimental plants had a single, first-day flower when placed in the pollination cage, while the background plants frequently had 10 or more flowers. Each day, we placed one or two new flats of experimental plants, each containing 32 plants, into the foraging arena. These plants remained within the arena for $2 \mathrm{~d}$. More than 100 fresh background plants were relayed into the arena each day. The locations of experimental and background flats were altered each day by rotating the flats to prevent the bees from learning to avoid the emasculated flowers. Each morning, we observed approximately four or five bees foraging on the flowers. They visited and probed the emasculated flowers just as they did the background flowers. Most experimental flowers received at least 10 visits by the bees while in the arena.

Corolla manipulation was imposed after experimental flowers were removed from the arena. A total of 135 experimental plants were placed in the pollination arena during the experiment. Of these, 24 naturally abscised their corollas before removal from the pollination arena and were thus excluded from the experiment. The 111 plants that retained their corollas were alternately assigned to two experimental categories, trimmed (55 plants) and control (56 plants).

\section{Bumblebee Pollination Experiment 2}

This experiment followed the same procedures as the first except that corolla manipulation was imposed at two different stages, both before and after flowers had been visited by bumblebees. These two treatments allow us to distinguish the effects of manipulation both before and after visitation. A total of 245 experimental plants were placed in the arena during this experiment, of which 102 were trimmed before placement in the arena (the "trimmed-before" treatment) and were randomly interspersed with the 143 nontrimmed plants. Among the trimmed-before plants, 14 naturally abscised their corollas before removal from the arena, and these plants were set aside to set seed. Among the nontrimmed plants, 55 of 143 had abscised their corollas. Untrimmed plants that retained their corolla were randomly subdivided into two further categories: "trimmed after," where the lower lobe of the corolla was now removed (52 plants) and "control" flowers that were left intact (36 plants). The trimmed-after and control groups of experiment 2 are essentially equivalent to the trimmed and control groups of experiment 1.

\section{Procedural Control Experiments}

For the hand-pollination experiment, flowers from 148 plants were emasculated and then hand-pollinated on the day of anthesis. Pollen was collected from a large outbred greenhouse population of M. guttatus, and a large amount was applied to the stigma of each plant. After hand-pollination, half of the plants were randomly assigned to the trimmed treatment, while the rest were left unmanipulated. For the corolla abscission experiment, flowers from 55 plants were randomly assigned as either trimmed or control on the day of anthesis. Each plant was monitored daily, and the number of days until the corolla either abscised or shriveled was noted. The experiments were conducted in a pollinator-free environment.

\section{Statistical Methods}

In each experiment except the corolla abscission experiment, we scored experimental plants for whether they successfully set seed and, if they did, the number of seeds produced by marked flowers. We tested for differences in the proportions of plants that set seed among experimental treatments using $\chi^{2}$ (Sokal and Rohlf 2000, chap. 17). We tested for differences among treatments in the average seed number of successful plants (those that set at least one seed) using 
ANOVA (Sokal and Rohlf 2000, chap. 9). Seed number exhibited a typical right-skewed distribution and, for this reason, was log transformed for statistical analysis (in all experiments). Although statistical comparisons were carried out on log-transformed seed numbers, untransformed seed numbers are given in the figures. For the corolla abscission experiment, we tested for differences in the number of days using ANOVA.

\section{Results}

\section{Procedural Control Experiments}

In the hand-pollination experiment, control plants produced an average of 98.7 seeds $(n=73, \mathrm{SD}=79.4)$, while the trimmed plants produced an average of 89.2 seeds $(n=75, \mathrm{SD}=76.0)$. This difference is not statistically significant $\left(F_{1,142}=1.25, P>0.05\right.$; fig. $\left.2 A\right)$, despite the large sample sizes. In the corolla abscission experiment, the corolla persisted on control flowers for an average of $4.61 \mathrm{~d}(n=28$, $\mathrm{SD}=1.89$ ), while the trimmed corollas persisted an average of $4.89 \mathrm{~d}(n=27, \mathrm{SD}=1.76)$. These means are similar to estimates in previous experiments (Arathi et al. 2002), and the difference between trimmed and control plants is not statistically significant $\left(F_{1,53}=0.32, P>0.05\right)$.

\section{Autogamy Experiment}

Of 112 flowers, 53 failed to produce any seed. A significantly higher fraction of trimmed plants failed to set seed than did control plants (table 2). Among plants that set seed, there was no significant difference between trimmed and control plants in seed number (trimmed: mean $=23.0$, $\mathrm{SD}=17.7$; control: mean $=22.4, \mathrm{SD}=26.6 ; F_{1,57}=1.063$, $P>0.05)$.

\section{Bumblebee Pollination Experiments}

In experiment 1 , a significantly higher proportion of trimmed flowers failed to set any seeds (table 2). Among plants that set seed, seed number was significantly lower for trimmed plants than control plants $\left(F_{1,88}=21.007\right.$, $P<0.001$; fig. $2 B$ ). Control plants set an average of 186.1 seeds $(n=54, \mathrm{SD}=113.2)$, while the mean of trimmed plants was $95.2(n=36, \mathrm{SD}=85.5)$. Flowers that naturally abscised their corollas before the imposition of treatments (and are not included in this comparison) produced a mean of 158.4 seeds $(n=18, \mathrm{SD}=105.2)$. In experiment 2 , a significantly higher proportion of control plants abscised their corollas while still in the pollination arena than trimmedbefore flowers $\left(\chi^{2}=18.005, \mathrm{df}=1, P<0.001\right)$. The abscised flowers produced a mean of 46.2 seeds $(n=55, \mathrm{SD}=42.3)$. Among plants that retained their corollas through the pollination period, the rate of reproductive failure (zero seed set) differed significantly among the three categories, with the highest rate of failure in the trimmed-before group, followed by the trimmed-after group (table 2). Among the 112 plants that set seed, seed number differed significantly among treatments (fig. $2 C ; F_{2,109}=156.29, P<0.001$ ). Control flowers had the highest fecundity $(n=33$, mean $=132.7, \mathrm{SD}=51.5)$, trimmed-after plants were intermediate $(n=40$, mean $=42.7$,
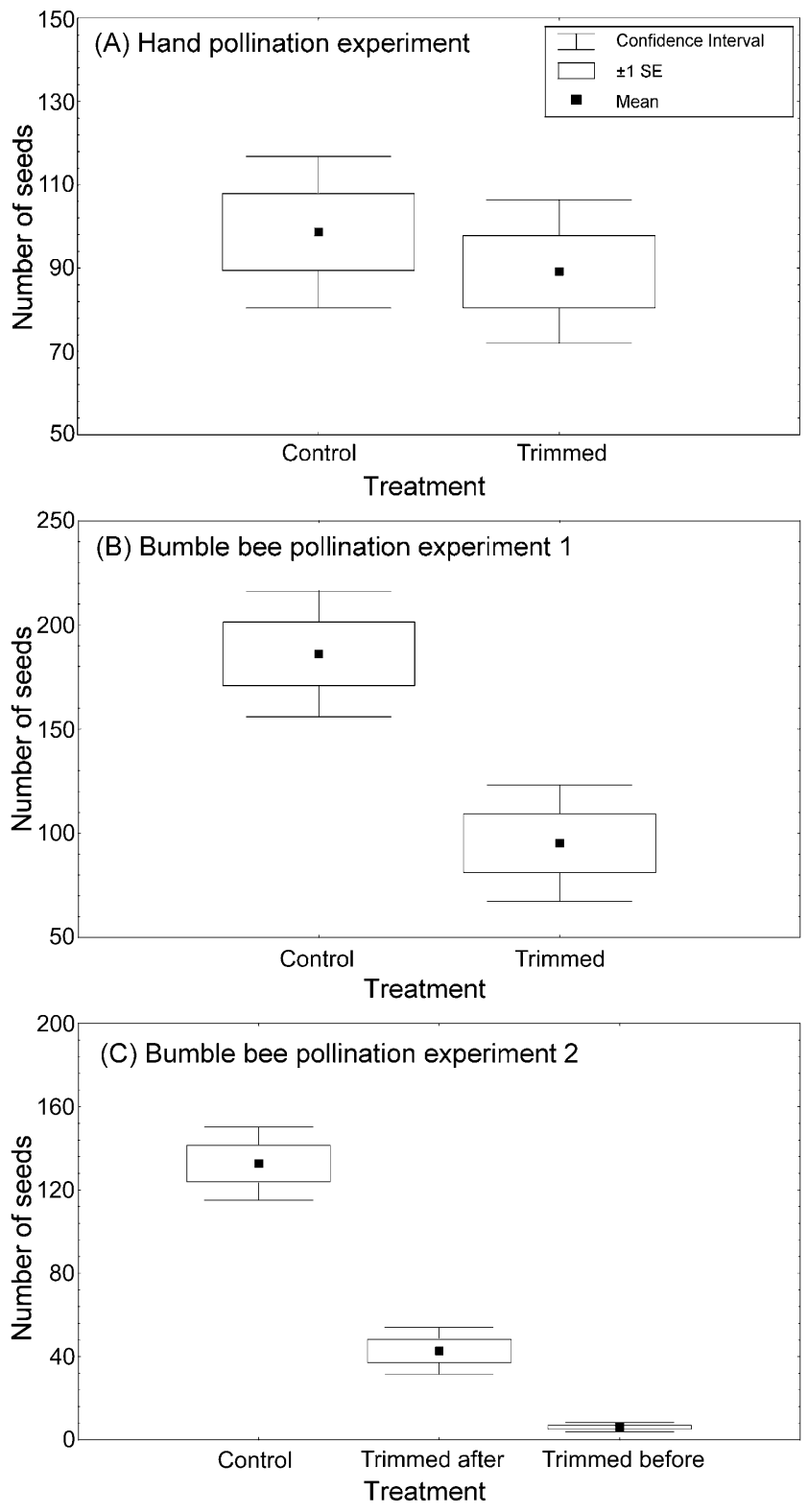

Fig. 2 Box-whisker plots depicting the number of seeds produced by plants in each experimental category within the $(A)$ handpollination experiment, $(B)$ bumblebee pollination experiment 1 , and $(C)$ bumblebee pollination experiment 2 . The central point denotes the mean, while the box includes $\pm 1 \mathrm{SE}$, and the whiskers demark the confidence interval on the mean.

$\mathrm{SD}=36.2$ ), while trimmed-before plants had the lowest fecundity $(n=39$, mean $=6.1, \mathrm{SD}=6.9)$.

\section{Discussion}

The corolla of Mimulus guttatus serves a range of functions. In the absence of pollinators, the corolla facilitates autogamy by collecting self-pollen (table 2). Seventy-three percent of control plants successfully set seed in the autogamy experiment as compared with only $21 \%$ of manipulated 
Table 2

Proportion of Plants That Fail to Set Seed in Each Treatment Category in Three of the Experiments

\begin{tabular}{lccc}
\hline & \multicolumn{2}{c}{ Treatment } & \\
\cline { 2 - 3 } Experiment & Control & Trimmed & $\chi^{2}$ \\
\hline $\begin{array}{l}\text { Autogamy } \\
\text { Bumblebee } \\
\text { pollination } 1\end{array}$ & $12 / 56$ & $41 / 56$ & $30.12^{* * * *}$ \\
$\begin{array}{c}\text { Bumblebee } \\
\text { pollination 2 }\end{array}$ & $2 / 56$ & $19 / 55$ & $17.35^{* * * *}$ \\
& $3 / 36$ & $\begin{array}{r}\text { Before: } 49 / 88 ; \\
\text { after: } 12 / 52\end{array}$ & $30.38^{* * * *}$ \\
\hline
\end{tabular}

*** $P<0.001$.

plants. When pollinators are present, corolla morphology facilitates both the receipt and dissemination of cross-pollen (fig. 2). Removal of the lower corolla lip reduced reproductive success nearly threefold in bumblebee pollination experiment 1 (considering both reproductive failure and differences in fecundity among plants that set seed). In bumblebee pollination experiment 2 , the fitness of control plants was nearly fourfold higher than that of trimmed-after plants. The trimmed-before flowers produced very few seeds. Finally, the indistinguishable responses of manipulated and control plants in the hand-pollination and corolla abscission experiments demonstrate that these results are not an artifact of the manipulation (of some kind of "wound response" to trimming).

The higher seed production of control flowers indicates that the lower corolla lip collects pollen. How are pollen grains physically transferred from corolla to stigma? The manipulations do not identify the proximate mechanism, but we have observed a number of potentially relevant morphological changes that occur as a flower ages. First, the distance between the stigmatic surface and lower corolla lip usually declines with flower age. In an unpollinated flower, the stigma often contacts the hairs of the corolla by the third or fourth day postanthesis. Second, many flowers exhibit "stigmatic curling" (Dole 1990): the lower lip of the stigma mouth curls progressively backward until the surface is effectively perpendicular to the corolla surface. Both changes increase the proximity of corolla and stigmatic surface. Third, the orientation of the flower generally changes as it ages. Most flowers are tilted upward (by an average angle of $24^{\circ}$ above horizontal in our sample) at anthesis but exhibit a distinct downward tilt by the time of corolla abscission (average angle $20^{\circ}$ below horizontal). Gravity should carry pollen away from the stigma when the flower tilts upward but toward the stigma when the flower points downward (fig. 1B).

Mimulus guttatus flowers have many fine hairs on the lower corolla lip, which may facilitate pollen collection (fig. 1A). Hairs have been implicated in pollen collection and/or dissemination in a variety of plants. In Wablenbergia, autogamy occurs as pollen grains deposited on the "pollen brush" are transferred to the stigmatic lobes (Anderson et al. 2000). Pollen-collecting hairs facilitate outcrossing in Campanula (Nyman 1993), and peristigmatic hairs delay self-fertilization in Lupinus nanus (Juncosa and Webster 1989). Corolla hairs may also act as "nectar guides" for foraging bees (Faegri and
Van der Pijl 1979, p. 29; Schemske and Bradshaw 1999). Our studies do not clearly isolate the pollination effects of corolla hairs in M. guttatus because we removed the entire lower portion of the corolla and not just the hairs.

\section{Facilitation of Self-Fertilization}

The mediation of autogamy by corolla morphology helps to explain several paradoxical results from previous $M$. guttatus experiments. Consider the timing of autogamy over the life span of a flower. In the absence of pollinators, autogamy occurs primarily toward the end of flower life span (4-5 d after anthesis for plants from the Iron Mountain population of M. guttatus; Arathi et al. 2002). However, by this stage, very little viable pollen remains within the anther lobes of a flower because it is released continually over the life span of the flower (Robertson et al. 1999; Arathi et al. 2002). The opportunity for direct transfer of pollen from anther to stigma at the end of floral life span is thus limited. However, indirect transfer becomes increasingly likely as a flower ages and the stigmatic surface comes in contact with corolla hairs harboring self-pollen. A similar mechanism for "delayed selfing" has recently been described in Collinsia verna (Kalisz et al. 1999).

The implication of the lower corolla lip in autogamy is also relevant to previous studies relating stigma-anther separation to the mating system of $M$. guttatus. Direct transfer of pollen to stigma may be more likely if the distance between stigma and anthers is small. Stigma-anther separation has been shown to influence the rate of selfing in many different species (Faegri and van der Pijl 1979; Belaoussoff and Shore 1995; Klips and Snow 1997; Eckert and Schaeffer 1998), including Mimulus ringens (Karron et al. 1997). However, several studies of $M$. guttatus have failed to find a strong relationship (Robertson et al. 1994; J. K. Kelly, unpublished data). The absence of a relationship is not surprising if selffertilization is primarily indirect. The distance between stigma and anthers should be less important if self-pollen is picked up from the corolla and not directly from the anthers.

\section{Facilitation of Outcrossing}

Our bumblebee experiments indicate that a large fraction of cross-pollination is indirect. Cross-pollen is transferred to the stigmatic surface long after a pollinator has departed from a flower. This conclusion follows from the large difference in seed set between control and trimmed flowers in bumblebee experiment 1 and between control and trimmedafter flowers in bumblebee experiment 2. In both comparisons, manipulation should have eliminated only indirect pollination. We have observed that bumblebees deposit a large amount of pollen on the corolla while foraging within the flower. The stigmatic surface is generally closed during this foraging period and so direct transfer is impossible. Taken together, the results from both experiments are consistent with our prior hypothesis that the touch-sensitive stigma of $M$. guttatus limits direct pollen transfer during visitation.

The comparisons in figures $2 B$ and $2 C$ do underestimate direct pollination in one important regard. They do not include plants that had abscised their corollas while in the pollination arena. Successful pollination induces corolla 
abscission in M. guttatus (Arathi et al. 2002). The mean seed sets of abscised flowers were intermediate to those of control flowers and trimmed or trimmed-after flowers. These seeds are likely the product of direct cross-pollination, although some indirect transfer might have occurred before removal of the plants from pollination arena.

The lower corolla lip is clearly essential to the initial interaction between flower and bee. In bumblebee experiment 2, the trimmed-before flowers produced very few seeds (fig. 2C). This result is consistent with the hypothesis that the lower lip of the corolla serves to attract pollinators in $M$. guttatus. However, the lower lip is certainly also important as a landing platform for pollinators. We observed that bees would approach trimmed flowers in bumblebee experiment 2 but could not forage effectively and had to work the flowers from unusual positions.

Our outcrossing experiments were conducted using a single species pair (M. guttatus and Bombus impatiens) within a laboratory foraging arena. Bumblebees (Bombus spp.) are important pollinators in natural populations of M. guttatus (Kiang 1972; Macnair et al. 1989), and Bombus has been used in previous laboratory pollination studies of M. guttatus (Robertson et al. 1999). We have noted visitation by three different bumblebee species at Iron Mountain (the source of plants in this experiment): Bombus edwardsi Cresson, Bombus mixtus Cresson, and Bombus melanopygus Nylander. It is important to acknowledge, however, that M. guttatus is pollinated by a variety of species in nature, and the relative importance of different species is likely to vary over its geographic range. For example, we have observed that Osmia bucephala Cresson (Megachilidae) is an important pollinator in one Oregon population (Dexter Reservoir; Kelly and Willis 2002), while Apis mellifera is likely to be the primary pollinator in many lower-elevation populations in California (N. Martin, personal communication).
To what extent are our results applicable to natural populations of M. guttatus? We expect that our conclusions concerning the functional significance of corolla morphology for the mechanical receipt and dissemination of pollen will prove relevant to many natural populations of $M$. guttatus and possibly to other species with "lipped" flowers. These results depend more on aspects of the floral morphology (which are faithfully represented in the laboratory) than on the searching behavior of the pollinator (which is likely to vary among species and may be very different in the field vs. the laboratory). Of course, the pollinator behaviors are likely to be a critical determinant of the relationship between corolla morphology and pollinator recruitment. Field studies are thus necessary to investigate the functional significance of corolla morphology in pollinator attraction.

\section{Acknowledgments}

We would like to thank H. Alexander, D. Crawford, A. Danielson-Francois, B. Harris, L. Holeski, Y. W. Lee, T. Marriage, C. D. Michener, K. Milne, M. E. Orive, M. Stearns, and two anonymous reviewers for their comments on the manuscript. H. Alexander, K. Loudon, and C. Martin provided experimental advice. J. Sandidge provided the photograph and C. Ardelean the line drawing in figure 1. K. Nus helped maintain a pesticide-free environment in the greenhouse, especially for the plants exposed to the bumblebees. Pollinators were collected by L. Holeski and G. Smick and identified by C. D. Michener. These experiments were supported by the Murphy Scholarship Foundation, National Science Foundation (NSF) grant DEB-9903758, and the NSF Experimental Program to Stimulate Competitive Research grant for Ecological Genomics.

\section{Literature Cited}

Anderson GJ, G Bernardello, P Lopez S, DJ Crawford, TF Stuessy 2000 Reproductive biology of Wablenbergia (Campanulaceae) endemic to Robinson Crusoe Island (Chile). Plant Syst Evol 223:109-123.

Arathi HS, A Rasch, C Cox, JK Kelly 2002 Autogamy and floral longevity in Mimulus guttatus. Int J Plant Sci 163:567-573.

Belaoussoff S, JS Shore 1995 Floral correlates and fitness consequences of mating-system variation in Turnera ulmifolia. Evolution 49: 545-566.

Carolin RC 1960 The structures in presentation of pollen to visiting insects in the order Campanales. Proc Linn Soc N S W 85:197-207.

Darwin CR 1877 The various contrivances by which orchids are fertilised by insects. J Murray, London.

Dole JA 1990 Role of corolla abscission in delayed self-pollination of Mimulus guttatus (Scrophulariaceae). Am J Bot 77:1505-1507.

Dytham C 1999 Choosing and using statistics: a biologists guide. Blackwell, London.

Eckert C, A Schaeffer 1998 Does self-pollination provide reproductive assurance in Aquilegia canadensis (Ranunculaceae)? Am J Bot 85:919-924.

Faegri K, L Van der Pijl 1979 The principles of pollination ecology. Pergamon, Oxford.

Futuyma DJ 1998 Evolutionary biology. Sinauer, Sunderland, Mass.
Grant KA 1966 A hypothesis concerning the prevalence of red coloration in California hummingbird flowers. Am Nat 100:85-98.

Harder LD, JD Thomson 1989 Evolutionary options for maximizing pollen dispersal of animal-pollinated plants. Am Nat 133: 323-344.

Juncosa AM, BD Webster 1989 Pollination in Lupinus nanus subsp. Latifilius (Leguminosae). Am J Bot 76:59-66.

Kalisz S, DW Vogler, M Fails, M Finer, E Shepard, T Herman, R Gonzales 1999 The mechanism of delayed selfing in Collinsia verna (Schrophulariaceae). Am J Bot 86:1239-1247.

Karron JD, RT Jackson, NN Thumser, ST Schlicht 1997 Outcrossing rates of individual Mimulus ringens genets are correlated with anther-stigma separation. Heredity 79:365-370.

Kelly JK, JH Willis 2002 A manipulative experiment to estimate biparental inbreeding in monkeyflowers. Int J Plant Sci 163: 575-579.

Kevan PG 1978 Floral coloration, its colorimetric analysis and significance in anthecology. Pages 51-78 in AJ Richards, ed. The pollination of flowers by insects. Academic Press, New York.

Kiang YT 1972 Pollination study in a natural population of Mimulus guttatus. Evolution 26:308-310.

Klips RA, AA Snow 1997 Delayed autogamous self-pollination in Hibiscus laevis (Malvaceae). Am J Bot 84:48-53. 
Macnair MR, VE Macnair, BE Martin 1989 Adaptive speciation in Mimulus: an ecological comparison of Mimulus cupriphilus with its presumed progenitor Mimulus guttatus. New Phytol 112: 269-279.

Mitchell-Olds T, RG Shaw 1987 Regression analysis of natural selection: statistical inference and biological interpretation. Evolution 41:1149-1161.

Nyman Y 1993 The pollen-collecting hairs of Campanula (Campanulaceae). I. Function and adaptive significance in relation to pollination. Am J Bot 80:1437-1443.

Robertson AW, A Diaz, MR Macnair 1994 The quantitative genetics of floral characters in Mimulus guttatus. Heredity 72: 300-311.

Robertson AW, C Mountjoy, BE Faulkner, MV Roberts, MR Macnair 1999 Bumble bee selection of Mimulus guttatus flowers: the effects of pollen quality and reward depletion. Ecology 80: 2594-2606.

Schemske DW, HD Bradshaw 1999 Pollinator preference and the evolution of floral traits in monkey flowers (Mimulus). Proc Natl Acad Sci USA 96:11910-11915.

Shetler S 1979 Pollen-collecting hairs of Campanula (Campanulaceae). I. Historical review. Taxon 28:205-215.

Sokal RR, FJ Rohlf 2000 Biometry. WH Freeman, New York.

Sprengel CK 1793 Das endeckte Geheimniss der Natur in Bau und in der Befurchtung der Blumen. F Vieweg, Berlin.

Vickery RK 1978 Case studies in the evolution of species complexes in Mimulus. Evol Biol 11:405-507.

Wade MJ, S Kalisz 1990 The causes of natural selection. Evolution 44:1947-1955.

Waser NM 1983 The adaptive nature of floral traits: ideas and evidence. Pages 241-285 in LA Real, ed. Pollination biology. Academic Press, New York.

Willis JH 1993 Partial self fertilization and inbreeding depression in two populations of Mimulus guttatus. Heredity 71:145-154.

1996 Measures of phenotypic selection are biased by partial inbreeding. Evolution 50:1501-1511. 
Copyright of International Journal of Plant Sciences is the property of University of Chicago Press and its content may not be copied or emailed to multiple sites or posted to a listserv without the copyright holder's express written permission. However, users may print, download, or email articles for individual use. 